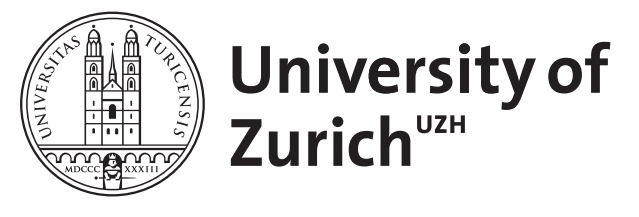

\title{
Future of heart valve surgery
}

Turina, M I

\begin{abstract}
In highly developed nations, valve surgery will be increasing applied in older people, with more co-morbidities and a higher incidence of concomitant coronary artery disease. Valve surgeons will be facing increased competition from the catheter-based procedures, both for valve repair and replacement; these are already applied clinically, and their numbers will rise in near future. Early mortality in double valve procedures and in combined CABG and valve operations remains substantial, and there is ample room for improvement of surgical results. New valve prostheses are slow in development, due to financial restraints and exceeding cost of certification. Tissue-engineered valves are being developed, but are not ready for larger clinical trials. Cardiac surgery is undergoing a rapid transformation; radical changes both in scope and workload of cardiosurgical units in Europe can be expected in near future. Socio-economic factors and recent advances in medical technology contribute to these changes.
\end{abstract}

DOI: https://doi.org/10.1016/j.ejctsup.2004.11.004

Posted at the Zurich Open Repository and Archive, University of Zurich

ZORA URL: https://doi.org/10.5167/uzh-153832

Journal Article

Published Version

Originally published at:

Turina, M I (2004). Future of heart valve surgery. European journal of cardio-thoracic surgery: official journal of the European Association for Cardio-thoracic Surgery, 26(1):S8-S13.

DOI: https://doi.org/10.1016/j.ejctsup.2004.11.004 
EUROPEAN IOURNAL OF

Review

\title{
Future of heart valve surgery
}

\author{
Marko Ivan Turina*
}

Clinic for Cardiovascular Surgery, University Hospital Zurich, Rämistrasse 100, Zurich CH-8091, Switzerland

\begin{abstract}
Summary
In highly developed nations, valve surgery will be increasing applied in older people, with more co-morbidities and a higher incidence of concomitant coronary artery disease. Valve surgeons will be facing increased competition from the catheter-based procedures, both for valve repair and replacement; these are already applied clinically, and their numbers will rise in near future. Early mortality in double valve procedures and in combined CABG and valve operations remains substantial, and there is ample room for improvement of surgical results. New valve prostheses are slow in development, due to financial restraints and exceeding cost of certification. Tissue-engineered valves are being developed, but are not ready for larger clinical trials. Cardiac surgery is undergoing a rapid transformation; radical changes both in scope and workload of cardiosurgical units in Europe can be expected in near future. Socio-economic factors and recent advances in medical technology contribute to these changes.
\end{abstract}

(C) 2004 Published by Elsevier B.V.

Keywords: Valve surgery; Combined CABG; Tissue engineering; Prostheses

\section{Increased life expectancy}

In the second half of the 20th century, an unprecedented prolongation of human life has been observed. Average life expectancy in the countries of the European Union (EU) rose almost 9 years from 1960 to 2000 (Fig. 1), and the increase was most marked in less developed EU countries. The surgeons will be treating an increased number of aged people; US expects that the aged population ( $>65$ years) will double by 2040 (Fig. 2); by that time it will reach 77 million, more than a quarter of total US population. Cardiosurgical consequences are obvious: degenerative heart disease (aortic stenosis, mitral regurgitation, heart failure, total AV block) will be encountered more frequently than before, and surgery will assume exceedingly complex proportion in this population with multifocal atherosclerosis. This fact is well reflected in the recent European Survey by Bruce Keogh [1], where the major increase has been observed in the segment of combined CABG and valve procedures.

\section{Reduced incidence of coronary heart disease}

This trend has been observed in highly developed nations since early sixties (Fig. 3), especially among males, and

\footnotetext{
it Presented at the EACTS Symposium for the Future of Cardiac Surgery, Frankfurt, Germany, July 1-2, 2004.

*Tel.: +41 1 2511287; fax: +4112511422.

E-mail address: marko.turina@chi.usz.ch
}

represents probably the cumulative effects of prophylactic measures, both primary and secondary, aimed at better control of blood pressure, as well as reduction of smoking, changes in life style and possibly better control of diabetes. This development is already reflected in reduction of coronary artery bypass grafting (CABG) procedures, which has been observed in recent years in highly developed nations, and will greatly change the scope and amount of work in cardiosurgical units.

\section{Rapid development of invasive cardiology}

In highly developed nations of Europe and North America, catheter interventions greatly outnumber the operative treatment of coronary atherosclerosis (Figs. 4 and 5), and STS database shows a $23 \%$ reduction of CABGs in recent years. ${ }^{1}$ The growth of invasive cardiology does not remain limited to PTCA and stenting of the coronary arteries. Percutaneous balloon mitral valvotomy is already established as a primary treatment of mitral stenosis [2], although the same technique is very unsatisfactory in the treatment of aortic stenosis. Percutaneous, catheter-based treatments of mitral insufficiency, both by edge-edge repair and reduction of posterior leaflet of the mitral valve via coronary sinus [3], are being explored, and one can assume that these

\footnotetext{
${ }^{1}$ http: / / www.ctsnet.org/file/STSNationalDatabaseSpring2004AdultCardiacExecutiveSummary.pdf Table 1.
} 


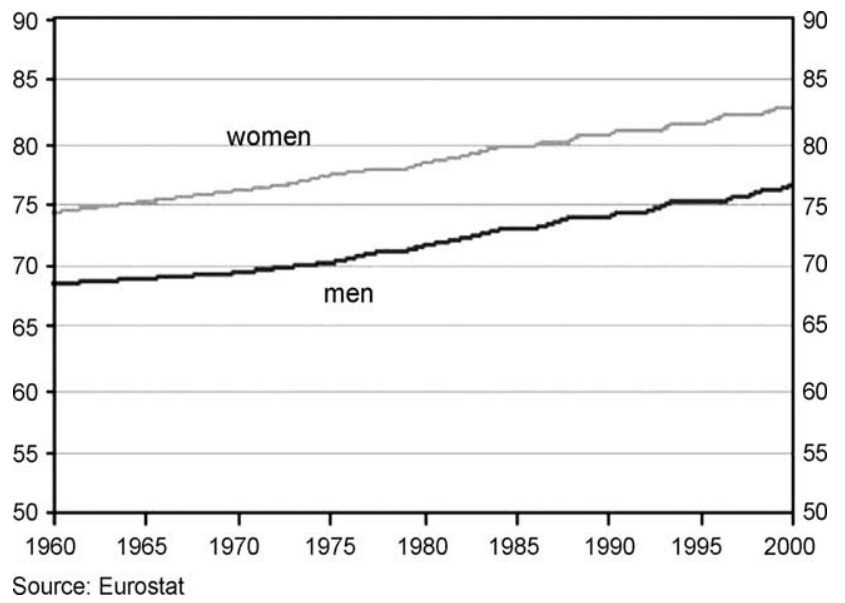

Fig. 1. Life expectancy for men and women, EU 15, 1960-2000.

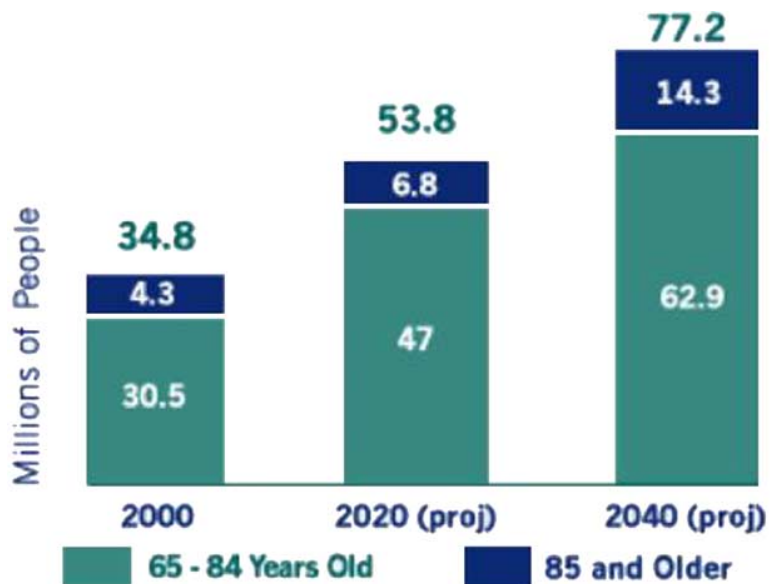

Source. Bureau of the Census. "Projections of the Total Resident Population by 5-Year Age Groups and Sex With Special Age Categories: Middla Series," Jan. 2000

Fig. 2. Elderly population.

developments, heavily sponsored by industry, will lead to larger clinical trials in near future. Pulmonary valve replacement by catheter technique is already established in pediatric population [4], and percutaneous aortic valve

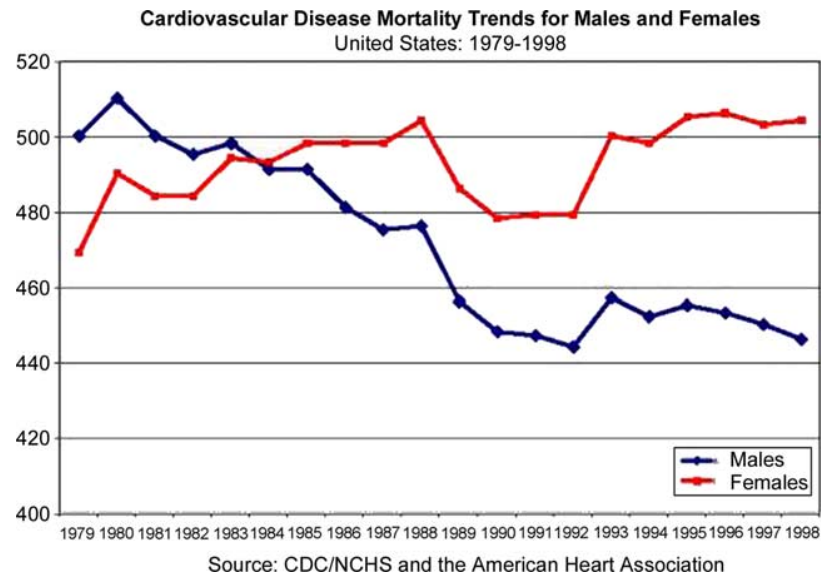

Fig. 3. Decrease of cardiovascular mortality in males.

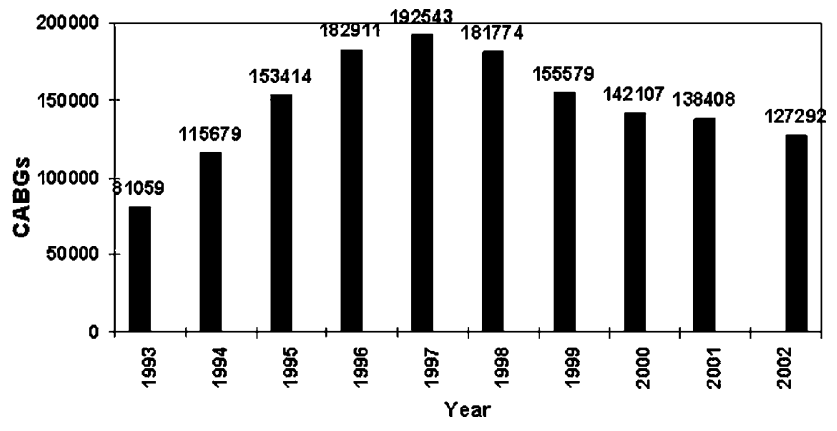

Fig. 4. CABG procedures in USA STS database, 1993-June 2002.

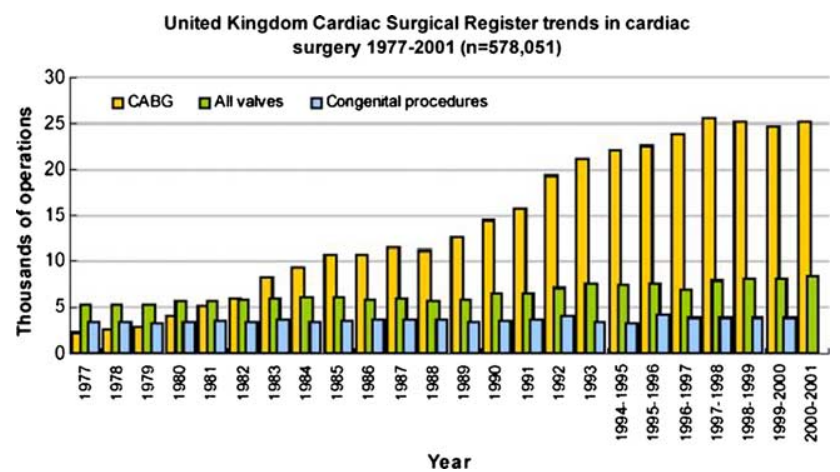

Fig. 5. Decrease of CABG procedures in UK.

replacement is being developed [5]. In spite of many setbacks, this development will continue, and cardiac surgeons can expect to lose a substantial part of their established field of valvular surgery, which will be taken over by invasive cardiologists. It is obvious that the surgeons, being unable to stop or block such a development, will have to adopt these techniques, both to assure the safety of new interventions, and to able to perform them together with catheter interventionists.

\section{Expected changes in the field of valve surgery}

In terms of operative techniques, only few changes have occurred in the last decade. Myocardial protection has been considerably improved, although the mortality of valvular procedures remains higher than in CABG, especially in combined procedures (CABG and valve) and in double valve operations (Table 1), as also shown in STS database. ${ }^{2}$ Major breakthrough is hardly to be expected in this particular area, both due to the increasing age of patient population, and to the diffuse atherosclerotic disease in coronary system and in the aorta. Patients rarely succumb to the operation itself: primary myocardial failure after surgery ('postoperative low output syndrome') can be controlled by drugs and by temporary heart assist devices (primarily IABP). Neurological mortality is assuming increasing proportion, especially in

\footnotetext{
${ }^{2}$ http: / / www.ctsnet.org/file/STSNationalDatabaseSpring2004AdultCardiacExecutiveSummary.pdf Fig. 8.
} 
Table 1

In complex valvular procedures, there is ample room for improvement in surgical results

\begin{tabular}{|c|c|c|c|c|c|c|c|c|c|c|c|c|}
\hline & \multicolumn{6}{|c|}{ Without CABG } & \multicolumn{6}{|c|}{ With CABG } \\
\hline & \multicolumn{3}{|c|}{ Initial } & \multicolumn{3}{|c|}{ Repeat } & \multicolumn{3}{|c|}{ Initial } & \multicolumn{3}{|c|}{ Repeat } \\
\hline & No. & Died & $\%$ & No. & Died & $\%$ & No. & Died & $\%$ & No. & Died & $\%$ \\
\hline \multicolumn{13}{|l|}{ Double valves } \\
\hline Mitral and aortic & 326 & 29 & 8.9 & 60 & 4 & 6.7 & 122 & 20 & 16.4 & 11 & 3 & 27.3 \\
\hline Mitral and tricuspid & 55 & 6 & 10.9 & 26 & 7 & 26.9 & 16 & 5 & 31.3 & 0 & 0 & 0.0 \\
\hline Aortic and tricuspid & 5 & 1 & 20.0 & 4 & 1 & 25.0 & 1 & 0 & 0.0 & 0 & 0 & 0.0 \\
\hline Other double valves & 4 & 1 & 25.0 & 0 & 0 & & 0 & 0 & 0.0 & 0 & 0 & 0.0 \\
\hline Double total & 390 & 37 & 9.5 & 90 & 12 & 13.3 & 139 & 25 & 18.0 & 11 & 3 & 27.3 \\
\hline
\end{tabular}

UKCSR: multiple open valve operations financial year ending 2001.

Table 2

Role of homografts is grossly overrated $(1.6 \%)$ !

\begin{tabular}{|c|c|c|c|c|c|c|}
\hline & \multicolumn{6}{|c|}{ Without CABG } \\
\hline & \multicolumn{3}{|c|}{ Initial } & \multicolumn{3}{|c|}{ Repeat } \\
\hline & No. & Died & $\%$ & No. & Died & $\%$ \\
\hline \multicolumn{7}{|l|}{ Aortic } \\
\hline Valvotomy/repair & 17 & 0 & 0.0 & 0 & 0 & 0.0 \\
\hline Mechanical valve & 1474 & 30 & 2.0 & 166 & 4 & 2.4 \\
\hline Bioprosthesis & 1480 & 65 & 4.4 & 85 & 8 & 9.4 \\
\hline Homograft & 48 & 0 & 0.0 & 25 & 1 & 4.0 \\
\hline Autograft & 24 & 0 & 0.0 & 2 & 0 & 0.0 \\
\hline Aortic total & 3043 & 95 & 3.1 & 278 & 13 & 4.7 \\
\hline
\end{tabular}

For comparison: in Germany 0.7\%; UKCSR: single open valve operations financial year ending 2001.

the combined CABG and valve procedures, and both morbidity and mortality of this complication are very high [6].

Development of valve prosthesis has been stagnant in the recent years, and no major breakthroughs are presently visible. Durable mechanical valves still need anticoagulation and are prone to thrombosis and embolism; a truly antithrombogenic mechanical valve has not been yet developed, in spite of the remarkable progress in heparin bonding. Biological valves are still not durable, and are only of limited use in younger population. Presently, they are used in exceeding numbers, due to the aging of the population being subjected to valve replacement. Recent statistics [7] show that in UK almost half of patients with aortic valve replacement receive biological valves. Homografts-due to the difficulties in obtaining good valves-play a minimal role, and their numbers are not expected to rise in the future (Table 2).

Valve repair plays a major role in mitral surgery, and the proportion of patients with this procedure is expected to rise, with surgeons gaining experience with various methods of valve repair (Table 3 ). In aortic surgery, various methods of aortic valve repair in the dilated aortic root are gaining acceptance, but the absolute numbers will probably remain low, due to the rarity of the condition (normal, tricuspid aortic valve with isolated dilatation of sinus portion of the ascending aorta). Ross procedure is very popular in children and young adults, but the absolute numbers remain low, due to the relative complexity of the surgical correction and necessity to implant another prosthesis in pulmonary position, with uncertain long-term results (Table 2 ).

Tissue engineering has played a major role in the development of autologous-cell, bench engineered valve prosthesis. Numerous publications have addressed this problem, and many animal studies have demonstrated the possibility to construct a non-thrombogenic valve prosthesis from autologous or homologous cells, derived from various sources [8,9]. Nevertheless, lasting function has been demonstrated only in the low-pressure circulation, and human implants have been rare. This field is expected to

Table 3

Mitral repair is not always possible (UKCSR 35\%)!

\begin{tabular}{|c|c|c|c|c|c|c|c|}
\hline \multicolumn{8}{|l|}{ Mitral } \\
\hline Valvotomy/repair & 502 & 9 & 1.8 & 25 & 5 & 20.0 & 255 \\
\hline Mechanical valve & 774 & 39 & 5.0 & 218 & 24 & 11.0 & 318 \\
\hline Bioprosthesis & 145 & 14 & 9.7 & 41 & 9 & 22.0 & 108 \\
\hline Homograft & 0 & 0 & 0.0 & 0 & 0 & 0.0 & 0 \\
\hline Other & 1 & 1 & 100.0 & 0 & 0 & 0.0 & 1 \\
\hline Mitral total & 1422 & 63 & 4.4 & 284 & 38 & 13.4 & 682 \\
\hline
\end{tabular}

For comparison: in Germany 43\%. 
grow in future, although technical problems remain substantial. A major capital investment will be necessary to provide cardiac surgeons with a workable tissue-engineered valve.

\section{References}

[1] First European Cardiac Surgical Database Report. Prepared by Dr Bruce Keogh and Dr Robin Kinsman on behalf of Dendrite Clinical Systems Ltd. Published by: Dendrite Clinical Systems Ltd. 2003; p. 20.

[2] lung B, Garbarz E, Michaud P, Helou S, Farah B, Berdah P, Michel PL, Cormier $B$, Vahanian A. Late results of percutaneous mitral commissurotomy in a series of 1024 patients: analysis of late clinical deterioration: frequency, anatomic findings, and predictive factors. Circulation 1999; 99:3272-8.

[3] Alfieri O, Elefteriades JA, Chapolini RJ, Steckel R, Allen WJ, Reed SW, Schreck S. Novel suture device for beating-heart mitral leaflet approximation. Ann Thorac Surg 2002;74(5):1488-93.

[4] Pedra CA, Justino H, Nykanen DG, VanArsdell G, Coles JG, Williams WG, Freedom RM, Benson LN. Percutaneous stent implantation to stenotic bioprosthetic valves in the pulmonary position. J Thorac Cardiovasc Surg 2002;124(1):82-7.

[5] Kuklinski D, Attmann T, Weigang E, Martin J, Osypka P, Beyersdorf F. Future horizons in surgical aortic valve replacement: lessons learned during the early stages of developing a transluminal implantation technique. Am Soc Artif Intern Org J 2004;50(4):364-8.

[6] Hogue CW, Murphy SF, Schechtman KB, Dávila-Román VG. Risk factors for early or delayed stroke after cardiac surgery. Circulation 1999;100:642-7.

[7] Fifth National Adult Cardiac Surgical Database Report 2003, The Society of Cardiothoracic Surgeons of Great Britain and Ireland, Dendrite Clinical Systems. 2004; p. 65.

[8] Jockenhoevel S, Zund G, Hoerstrup SP, Chalabi K, Sachweh JS, Demircan L, Messmer BJ, Turina M. Fibrin gel-advantages of a new scaffold in cardiovascular tissue engineering. Eur J Cardiothorac Surg 2001;19(4):424-30.

[9] Flanagan TC, Pandit A. Living artificial heart valve alternatives: a review. Eur Cells Mater 2003;6:28-45.

\section{Appendix. Conference discussion}

Dr J. Pomar (Barcelona, Spain): As you mentioned at the end, thromboembolism is one of the limitations. Do you think the new antithrombotic drugs may help or may change or modify the future? There is a few now coming, like ximelagatran, for instance, which has not been used as anticoagulation treatment for valve replacement, but it seems to be easier to control and have less side effects than older drugs like coumadin or so. Do you think it is going to make an important difference or not?

Dr Turina: I think they are going to make an important progress in the treatment, especially the platelet inhibitors, which are now being analyzed in a much more effective fashion. There are huge differences in individual responses among the patients, and present approach with everybody receiving 100 aspirin or $75 \mathrm{mg}$ of Plavix is a gross oversimplification. The problem of resistance to anticoagulation will be an important one, but still I do not see in near future a mechanical valve which will need no anticoagulation.

Dr Pomar: Axel (Axel Haverich), maybe you have some input on the different use of getting the INR in Germany today at home, not in the hospital, as we have been using for years, and also about some particular valves having only antiplatelets.

Dr A. Haverich (Hannover, Germany): There was a trial that was discontinued last week with one mechanical valve. Patients were put on aspirin only. Because of one fatality, the trial was discontinued.

In the area of mechanical valves, I don't see that we are finding much progress. Yesterday I heard that even with ximelagatran and newer drugs that the bleeding complications may actually be similar to what we see in the coumadin treatment.

But for a meeting like this, I am sorry to say, and your time for preparation was very short, Marko (Marko Turina) but the flavor of this presentation should be different. We should not talk about the problems that we have with the current design that we have been talking about for the last 20 years and saying that the homografts play such an important role. The flavor of these talks, looking to the future should be not that tissue engineered grafts would be available only in the far future. There have been attempts of using tissue engineered valves in the last five years. There are the first valves coming out now clinically, like the Konertz group in Berlin, who has done nearly 150 implants, in the pulmonary position, of course.

And I think we should not say, well, these are the problems and the mortality is high. I think the flavor should be, we have these problems and we have to look that the mortality comes down and this would be the strategy to get this done, number one. This is how we not only improve survival, operative and long-term, but we also improve quality of life for the patient. We must talk about pediatric use, that we have valves that would grow with the patient and see with a more optimistic fashion into new developments. I see tissue engineered valves as a potential huge progress.

I would like to make a comment about the mortality in the present and in the future. In response to your question about the operative mortality being higher, we must address the septum, since it is a key link to survival because the right heart failure that develop may be fatal. Until now we have accepted the concept that the postoperative septum that is akinetic or hypokinetic postoperatively is a commonplace phenomena. This is wrong because I believe this complication is related to stunning that results from inadequate protection. We must then study the septum before and after the procedure to determine if the septum is working or not working. If it is not working postoperatively, yet worked preoperatively, this indicates the septum sustained intraoperative damage. Management of this complication means that your techniques of protection must be changed to allow the septum work normally. A good way to evaluate this process in your center is to review your results after $O P C A B$ procedures where your cardioplegia methods are not used, and the septum works every time. This avoidance of damage occurs because you have not injured this structure. We use the integrated cardioplegic technique to avoid damage and do not see septal injury. However, the barometer of success is presence or absence of septal damage. Therefore it does not matter which cardioplegic technique is used so long as septal injury is avoided. If your method causes damage, it should be changed. The positive consequence of this change will be that right heart failure will not occur.

Now let us assume that we solve the intraoperative problem in each instance, and thus assure $100 \%$ hospital survival following replacement of one valve or two valves. We must then look at long-term mortality, and longitudinal studies show very clear findings that are discouraging. Analysis of late results in patients with aortic or mitral insufficiency that present with $<40 \%$ ejection fraction, and large ventricular size shows only $30 \% 10$ year survival. This means that $70 \%$ of these patients will be dead in 10 years, regardless of how perfectly the valve replacement or repair corrects the insufficiency, and despite complete absence or operative mortality. The underlying reason is that we have only addressed the valve and did not address the ventricle. These patients succumb because of the complications of heart failure, which is the major health hazard that Friedhelm Beyersdorf talked about in his introduction. They develop chronic CHF or arrhythmic death, and our potential management change is to begin to look at how we change ventricular form at the time we correct the underlying valve problem. The geometric problem that follows valve insufficiency is the development of a spherical ventricle. This abnormal dilated chamber dimension is similar to the spherical ventricle that happens with ischemic heart failure. The difference with valvular cardiomyopathy is that all the muscles are alive; but the form is abnormal and we must consider how to fix this problem

My belief is that the future requires that we must deal with both the valve and the ventricle. As this new vantage point develops, a whole new look will emerge at what we do intraoperatively, so that the cardiac surgery arena will change as we begin to treat another target-the ventricle.

Dr T. Wahlers (Jena, Germany): Another point I think we should think about life quality after valve surgery in the older age group. With regard to the mortality we observe, I think we have to provide figures that life quality in a 90 -year-old man, for example, is good even if he lives longer only two to three to four years.

We need competitive data for the cardiologists facing the new interventional procedures coming up to advocate that cardiac surgery in these old patients is worth the effort and money spent.

There are no clear figures available. We have these unclear survival figures from the literature. You now showed clear figures from the UK registry, which are much better, but there are no long-term figures available in order to say it is good to operate on a 90-year-old. The only argument we are always giving is that our personal mortality is low in these type of patients. 
Dr Turina: There have been a number of recent papers in our Journal, addressing the problem of the quality of life after surgery, and it is surprising that there is a substantial group of patients, especially in coronary surgery, where the quality of life does not improve after operation, or even deteriorates. It is basically the brain complications of procedures, both coronary and valves, which make the patient suffer.

Dr J. Vaage (Oslo, Norway): We are talking about two different directions here in valve surgery: it is tissue engineered valves or the percutaneous repair or implantation. Even if a tissue engineered valve is very, very good, you still have the surgery, and if we look at the progress in endovascular procedures, I think it is quite logical that we will during the next 10 years look into a large improvement in this and how this can also be done with valves. And society and patients, they always want a percutaneous procedure. If surgeons still want to implant valves in the future, they also have to go to the cath lab and start training also in the cath lab.

Mr R. Guezuraga (Minneapolis, MN, USA): I am Bob Guezuraga from Medtronic, and I am the nonsurgeon that is here, so I look at this from a business perspective.

With respect to mechanical valves, there isn't a lot of investment going on in this area. I would say that the last valve that was approved here in Europe and yet to be approved in the United States is the valve that Medtronic designed. When I approved that project within Medtronic, it wasn't because I thought there was a tremendous future growth for mechanical valves, it was to fill out a basket of product offerings. The future within the valve business, where I do see the growth, where the investments are being made, is on the biological side and also tissue engineered.

But this whole concept of percutaneous repair and then hopefully one day the delivery of an aortic valve through a percutaneous technique is going to be a reality, because the investment dollars are going there. The research institutions, the companies that are in the business today that are putting $\$ 30$ and $\$ 40$ million dollars a year into R\&D are putting the money in those areas, and those are budgets that are much higher than I am sure most of the universities have in their smaller labs, important labs nonetheless, that is the direction that I see it going.

We are talking about having to use drugs associated to mechanical valves, and if we can get the durability and the performance of the biological valves, then we have the best of all worlds, and that is where I see the future going.

The concept of percutaneous is something that we are going to have to learn how to deal with: how do we get that valve there, how do we place it, what do we do with the native valve that is already in that position?

Dr O. Alfieri (Milan, Italy): To have better long-term results you have to operate on patients early in the course of the disease, before left ventricular dysfunction occurs; but cardiologists are generally against this because of the complications related to the artificial valves. I wonder whether it could be useful to stratify patients to know the valve-related complications according to the stage of the disease.

Dr Turina: I am still observing that mortality after valve surgery varies very much among different countries in Europe. In Switzerland patients are referred for aortic valve replacement much earlier, because the cardiologists have learned that left ventricular function in many patients does not improve after valve replacement, due to the variable amount of myocardial fibrosis. We are advocating surgery at the first signs of deterioration in the left ventricular function, when the wall thickness or left atrial size increase, or at the first onset of atrial fibrillation. So I think the indication for valve surgery is changing, but you must keep the mortality of primary aortic valve procedure below $1 \%$, and in the mitral valve repair at less than $0.5 \%$.

Dr Alfieri: Certainly in those cases the valve-related complication rate is much lower, but this has not been clearly proved. A potential increase of candidates for valve surgery can be seen.

Dr Turina: I can tell you an interesting observation. Ludwig von Segesser and myself have been looking for patients who would be candidates for the Batista procedure. I never see a good patient for a Batista procedure; I never see a failing left ventricle with a length diameter of more than $10 \mathrm{~cm}$, because they are treated so well with various drug combinations that this deterioration simply does not occur. So the differences in valve surgery mortalities in Europe, are at least in part determined by the timing of surgery.

Dr F. Beyersdorf (Freiburg, Germany): I would like to make two comments. First, what you just said with the percutaneous implantation of valves, I think that we have to have in our ORs the equipment for doing X-ray. Very seldom we have it today. And the next step will be that the new MR techniques will allow us maybe to even operate in the MR setting, because it is a half open one, and in Zurich I think you have already one where it is half open and tiny slim people can stand there doing some sort of surgery in the chest somewhere. So I think this will be the next development, and if you look to the $\mathrm{X}$-ray companies and the imaging companies, they are producing machines where in the future you might be able to do surgery using this kind of visualization technique.

Second, you said that the mortality in valve surgery is relatively high, which is correct. One of the reasons I think is that we are treating 90-year-old patients, and even though the heart is fine after the operation, they are still 90 years old. They have COPD, renal disease, etc. We need more exchange with our other colleagues, who care for the patient pre-, intra- and postoperatively.

Dr C. Mestres (Barcelona, Spain): I totally agree with Friedhelm Beyersdorf. I think it is a fundamental point. So we should not send anybody to the cath lab. We must create our cath lab. I think there are some experiences. We still do this thing, this wire still, this is myself, keep doing peripheral angioplasties just to keep this thing alive. And so the department should be responsible for that. When everything goes for simplicity, we must recall that.

I remember in the city of Frankfurt coming to visit a fellow eight years ago in a small clinic, at Hoechst Clinic here, called Wolf Stelter, who was very famous because he was one of the pioneers in abdominal aortic repairing through an endovascular prosthesis. He was a general surgeon assisted by an orthopedic surgeon in the operating room, so far away from what is very complicated today. So I think we must build our cath lab by doing whatever thing in the operating room. I think it is a fundamental issue for the future. This is why I totally agree with Friedhelm. So we must lead this move.

Dr G. Gerosa (Padova, Italy): I would like to take advantage of the comments of the last discussants. I appreciated what you said, where is the future? I believe that the lesson learned from the past from the stent business, the future is where the money is going to be put for future developments and for research technologies. So the future would be for endovascular implantation prostheses.

Regarding timing of surgery, yes, there is something wrong with timing of surgery with some valve disease, but the timing for a percutaneous procedure ruled by the cardiologists will be totally different. So definitely we are going to treat advanced valve disease with percutaneous procedures.

And also I would like to go back to Axel Haverich's highlight about tissue engineering. Tissue engineering is not in competition with endovascular valves, because you can put together the two technologies: you can implant using percutaneous technologies tissue engineered valves. But I would be really cautious about the experience that you mentioned right now, because there was a nice paper in Science last week dealing with the fact that premature papers can blast the entire field of research. So I would really be cautious before going into the clinical field with the application of tissue engineered valves, because we are a little bit far from that.

And finally, my last remarks, there are a few groups in Zurich and Hannover and Boston and ourselves in Padova dealing with tissue engineered valves, and the upscale of tissue engineered products will be a major issue, because I don't think-and I would like to hear from the manufacturers-I don't think that the manufacturers can scale up tissue engineered products, whereas this can be, let's say, confined to single institutions.

Mr B. Keogh (Birmingham, UK): We have an interventionist in the audience, Dr Dawkins, and I would like to ask his view. He has heard us say that as surgeons we should attempt to be involved in the percutaneous insertion of valves given that we recognise that is where the future lies. The reality is that cath labs are generally administered and financed through cardiology departments, MRI facilities are generally in radiology departments and under the control of radiologists. So, my question to Keith is how does he see the reality of surgeons trying to gain access to those facilities and the funding for them.

Dr K. Dawkins (Southampton, UK): I have been sitting here listening with interest to a very balanced view of cardiologists. The problem that was just raised about radiologists, radiologists don't have beds. Beds are power, and if you don't have beds you can't investigate patients. The turf wars in relation to radiology and cardiology are being lost throughout the whole world to cardiologists. The mindset of cardiologists is more like cardiac surgeons: they are more aggressive, they are more go-getting, and the industry is putting millions, millions of dollars into cardiology, in all aspects, as is the pharmaceutical industry. So the money is going to stents, is going to devices, I am sure it is going to valve technology, but it is actually going into cardiology, and cardiologists are grabbing this and running forward with it.

The prospects of you teaching surgeons in an operating room environment to do procedures that cardiologists take years to train in strikes me as bizarre. I mean, you could start doing gynecology in a cardiac operating room if there 
is nothing else to do. But why would you try and pick up a specialty which is well developed and is currently being run by arguably the most aggressive group in your hospital? I think it is very far-fetched to think that you will take over that turf from cardiologists when, in many senses, the surgical budget is being redirected to cardiology for drug-eluting stents or whatever.

So you need to refine, I think, your areas of expertise and develop them as surgeons. You are trained as surgeons. We get called to the operating room when people try to put an intra-aortic balloon pump in, you know, a junior surgeon, and has destroyed the artery because they don't know how to do these sorts of things. And Axel, I can see, can hardly contain himself.

Mr J. Monro (Southampton, UK): Keith (Keith Dawkins), sorry, while you still have the microphone, can I just ask how you see yourself or your colleagues doing these percutaneous insertions of aortic valves? I seem to remember you did some balloon valvotomies on aortic valves a few years back in people who were perhaps at the time felt to be too old or sick for surgery, and that didn't last very long.

Dr Dawkins: I am going to say a few words about percutaneous valve techniques. I think it is a niche, I really think it is a niche at the moment, but it is an area that people are going to develop, and of course it is an area the extreme end, you know, the triple lutz end of interventional cardiology in terms of manual dexterity and understanding how you move things within the heart from minimally invasive techniques. It is the very wrong end for cardiac surgeons to start in percutaneous techniques, in my opinion, my humble cardiology opinion.

Dr Alfieri: We have started a kind of experiment putting a fully trained cardiac surgeon in the cath lab to start a sort of cross training. This is going on since a couple of months and after one week this surgeon was able to do his first coronary angiogram and then PTCAs and so on.

In regard to percutaneous valve procedures, there are a few things which are different from coronary interventions. First, the gatekeeper is not the interventional cardiologist, because valve patients come from clinical cardiologists who can refer patients directly to the surgeon. Secondly, nobody more than a cardiac surgeon knows the lesions responsible for valve dysfunction.

In addition, the rate of complications is not low, and the problems can only be taken care of by surgeons.

Finally, the access might require surgical preparation of the vessels.

For all these reasons, I think that surgeons should be involved in the percutaneous procedures.

I have a question for industry people: in regard to percutaneous valve repair/replacement techniques, are you going to involve groups with cardiac surgeons fully involved in these programs?

Mr Guezuraga: I agree with you. The complication rates are very, very high starting off, and industry is going to work with the cardiac surgeon in order to be able to do the initial work, and it will go to those cardiac surgeons who embrace this and want to do it. But at the end of the day when the techniques are developed, whether it be repair or replacement, it will go to the group that accepts it, and if the group that accepts it is the cardiac surgeons because they were involved in the development and have the skill sets, then people from my business will be selling them product on a worldwide basis. If it goes to the cardiologists because there is a high level of acceptance there (it is all related to risk and the amount of data that is associated to where the state of the art is at that point in time) and the cardiologists are willing to move forward more aggressively, then my vascular sales force will be talking to the cardiologists.

Dr Turina: I can give you a piece of information when Andreas Gruntzing was starting the whole business of PTCA in Zurich in 1977/1978. I was doing the so-called surgical backup, and the incidence of complication among the first 88 patients (the paper was published in the Annals of Thoracic Surgery) was $11 \%$ : These patients were taken urgently to the operating room, a part of them under continuous resuscitation. We had a substantial number of complications, but it didn't stop the rapid spread of PTCA. 